Steer, J.H., Mann, T.S., Lo, S.Z.Y., Inglis, J.J., Yap, H.S., Henry, P.J. \& Joyce, D.A. (2013). Early induction of uncoupling protein-2 in pulmonary macrophages in hyperoxiaassociated lung injury. Inhalation Toxicology, 25(9), 544-552.

(C)2013 Informa Healthcare USA, Inc.

This is pre-copy-editing, author-produced version of an article accepted for publication in Inhalation Toxicology following peer review. The definitive published version (see citation above) is located on the article abstract page of the publisher, Informa Healthcare.

This version was made available in the UWA Research Repository on 1 August 2014 in compliance with the publisher's policies on archiving in institutional repositories.

Use of the article is subject to copyright law. 


\section{Early induction of uncoupling protein-2 in pulmonary macrophages in hyperoxia-associated lung injury.}

James H. Steer, Tracy S. Mann, Susan Z. Y. Lo, Julia J. Inglis, Huey S. Yap, Peter J. Henry, David A. Joyce*

School of Medicine \& Pharmacology, University of Western Australia, 35 Stirling Highway, Crawley, Western Australia, Australia 6009

\section{*Corresponding author:}

David A Joyce, MB BS MD FRACP, Pharmacology, Pharmacy and Anaesthesiology Unit, School of Medicine \& Pharmacology, University of Western Australia, 35 Stirling Highway, Crawley, Western Australia, Australia 6009. Tel +618 9346 2569; Fax +618 9346 3469; Email: david.joyce@uwa.edu.au

\section{Email addresses, other authors:}

James Steer: jay.steer@uwa.edu.au: Tracy S. Mann: tracy.mann@uwa.edu.au; Susan Z. Y. Lo: szylo@hotmail.com; Julia J. Inglis: julia.inglis@uwa.edu.au; Huey S. Yap: huey.yap@uwa.edu.au; Peter J. Henry: peter.henry@uwa.edu.au 


\section{Abstract}

Context. High concentrations of inspired oxygen contribute to the pathogenesis of neonatal bronchopulmonary dysplasia and adult acute respiratory distress syndrome. Animal models of hyperoxia-associated lung injury (HALI) are characterised by enhanced generation of reactive oxygen species (ROS) and an adaptive anti-oxidant response. ROS contribute to pathogenesis, partly through enhancing pro-inflammatory activity in macrophages. Uncoupling protein-2 (UCP2) is an inner mitochondrial membrane protein whose expression lowers mitochondrial superoxide $\left(\mathrm{O}_{2}{ }^{-}\right)$production. UCP2 therefore has potential to contribute to anti-oxidant response. It is inducible in macrophages.

Objectives and Methods. We hypothesized that induction of UCP2 occurred in response to pulmonary hyperoxia in-vivo and that expression localised to pulmonary macrophages. We then investigated mechanisms of UCP2 regulation in hyperoxia-exposed macrophages invitro and correlated changing UCP2 expression with mitochondrial membrane potential $\left(\Delta \psi_{\mathrm{m}}\right)$ and $\mathrm{O}_{2}{ }^{--}$production.

Results. UCP2 is induced in lungs of mice within $1 \mathrm{hr}$ of hyperoxia exposure. Induction occurs in pulmonary alveolar macrophages in-vivo, and can be replicated in-vitro in isolated macrophages. UCP2 mRNA does not change. UCP2 increases quickly after the first hyperoxia-induced burst of mitochondrial $\mathrm{O}_{2}{ }^{\cdot-}$ generation. Suppression of $\Delta \psi_{\mathrm{m}}$ and mitochondrial $\mathrm{O}_{2}{ }^{--}$production follow and persist while UCP2 is elevated.

Discussion and Conclusions. Induction of UCP2 is an early response to hyperoxia in pulmonary macrophages. The mechanism is post-transcriptional. UCP2 induction follows a transient rise in mitochondrial ROS generation. The subsequent falls in $\Delta \psi_{\mathrm{m}}$ and mitochondrial $\mathrm{O}_{2} \bullet^{-}$support the notion that regulable UCP2 expression in macrophages acts to 
contain mitochondrial ROS generation. That, in turn, may limit inappropriate proinflammatory activation in HALI.

\section{Key Words:}

Uncoupling protein-2; Macrophage; Reactive oxygen species; Mitochondria; Hyperoxiaassociated lung injury 


\section{Abbreviations:}

ARDS: acute respiratory distress syndrome; BAL: bronchoalveolar lavage; BMDM: murine bone marrow-derived monocyte/macrophages; BPD: bronchopulmonary dysplasia; CCCP: carbonyl cyanide m-chlorophenylhydrazone; CSF-1: macrophage colony stimulating factor1; DHE: dihydroethidium; DMEM: Dulbecco's modified Eagle medium; FCS: foetal calf serum; Et: ethidium; HALI: hyperoxia-associated lung injury; HBSS: Hanks balanced salt solution; JC-1: 5,5',6,6'-tetrachloro-1,1',3,3'-tetraethylbenzimidazol carbocyanine iodide; $\Delta \psi_{\mathrm{m}}$ : mitochondrial membrane potential; NDS: normal donkey serum; ROS: reactive oxygen species; $\mathrm{O}_{2}{ }^{--}$: superoxide; RPLP0: ribosomal phosphoprotein large P0; UCP2: uncoupling protein-2; VDAC1: voltage-dependent anion channel-1. 


\section{$\underline{\text { Introduction }}$}

Hyperoxia-associated lung injury (HALI) is a consequence of sustained exposure to high concentrations of inspired oxygen. It is understood to contribute to the pathogenesis of neonatal bronchopulmonary dysplasia (BPD) (Bourbon et al., 2005) and adult respiratory distress syndrome (ARDS) (Branson and Robinson, 2011, de Graaff et al., 2011), when sustained high inspired oxygen concentrations are required in treatment. In those clinical conditions, hyperoxia acts on the background of an immature respiratory system in BPD or lungs that already harbour serious pathology in ARDS, making the exact contribution of HALI difficult to measure. HALI has been successfully modelled in many other mammalian species (Fracica et al., 1991, Frank et al., 1978, Matute-Bello et al., 2008). Early pathology includes death of alveolar type I pneumocytes and capillary endothelial cells, accumulation of polymorphonuclear leukocytes, macrophage activation and oedema (Donnelly et al., 1993, Gore et al., 2010). Fibroblast proliferation and scarring follow in survivors (Matute-Bello et al., 2008). In human BPD and ARDS, the pathology reflects the sum effects of the background condition and hyperoxic exposure (Altemeier and Sinclair, 2007, Bourbon et al., 2005).

Oxygen toxicity is substantially mediated through reactive oxygen species (ROS) (Freeman and Crapo, 1981, Freeman and Crapo, 1982, Fridovich, 1978), including the generation of superoxide $\left(\mathrm{O}_{2}{ }^{-}{ }^{-}\right)$in mitochondria (Freeman and Crapo, 1981, Turrens et al., 1982, Brueckl et al., 2006). Further reduction of $\mathrm{O}_{2}{ }^{--}$yields hydrogen peroxide and hydroxyl radical. Known critical targets of ROS attack include lipids, transporters, pro- and anti-apoptotic proteins, transcription factors, kinases and mitochondrial proteins (Gore et al., 2010, Halliwell, 2007). Systems of low molecular weight reductants, sulfhydryl-containing protein reductants, superoxide dismutases and peroxidases act to detoxify ROS generated in mitochondria (Limon-Pacheco and Gonsebatt, 2009). These are complemented by cytosolic and 
extracellular antioxidant systems. Elements of both the mitochondrial and extramitochondrial systems are inducible, providing an adaptive response to increased oxidative stress that can be invoked during the non-physiological stress of hyperoxia (Gore et al.,

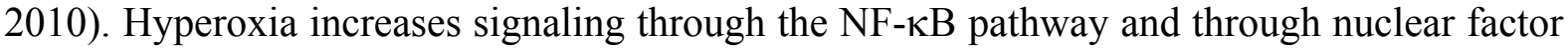
erythroid derived 2-related transcription factor 2 (Nrf2) (Cho et al., 2002). This contributes to the induced anti-oxidant response.

Polymorphonuclear leukocytes and macrophages represent the innate immune response in HALI, BPD and ARDS (Cho et al., 2002, D'Angio et al., 1995). The canonical NF-אB pathway transduces inflammatory and survival signaling in macrophages (Pagliari et al.,

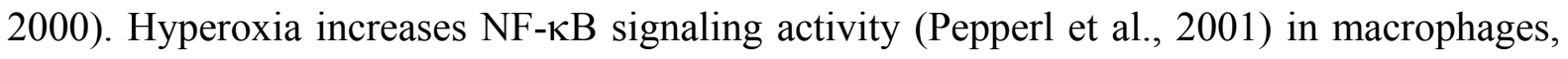
an effect that is understood to be ROS-mediated (Gore et al., 2010, Morgan and Liu, 2011). As a presumed consequence, NF-kB signaling is enhanced in models of HALI (Gore et al., 2010). A similar increase in NF- $\kappa B$ activity occurs in alveolar macrophages of ARDS patients (Schwartz et al., 1996). In experimental HALI (Gore et al., 2010, D'Angio et al., 2004, Donnelly et al., 1993) and ARDS (Perl et al., 2011, Tsushima et al., 2009) this is accompanied by increases in the NF- $\kappa B$-regulated macrophage cytokines, IL-1 $\beta$, TNF $\alpha$ and

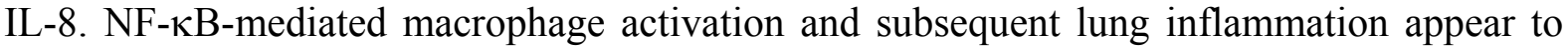
play a key role in BPD pathogenesis also (Blackwell et al., 2011).

In addition to the ROS-inducible NF- $\mathrm{B}$ and Nrf2 antioxidant pathways, we have recently observed that macrophages rapidly increase expression of mitochondrial uncoupling protein2 (UCP2) in circumstances of increased mitochondrial ROS generation (Giardina et al., 2008). UCP2 belongs to the superfamily of inner mitochondrial membrane anion-carrier proteins that also includes UCP's 1, 3, 4 and 5, the adenine nucleotide translocases and the phosphate, oxoglutarate/malate, carnitine, citrate, ornithine and dicarboxylate carriers 
(Nicholls and Locke, 1984, Nedergaard and Cannon, 2003, Fleury et al., 1997). It is nuclearencoded. UCP2 expression in the inner mitochondrial membrane lowers mitochondrial $\mathrm{O}_{2}{ }^{--}$ production (Negre-Salvayre et al., 1997). This is consistent with a mild uncoupling function which dissipates the mitochondrial membrane potential $\left(\Delta \psi_{\mathrm{m}}\right)$ (Miwa et al., 2003). The importance of UCP2 regulation is revealed in macrophages of homozygous uсp2 genedeleted mice, where increased ROS generation perturbs innate immune function (Arsenijevic et al., 2000). Isolated cells of various lineages have shown comparable results (Kizaki et al., 2002, Teshima et al., 2003).

Approximately one third of the total organ expression of UCP2 in lung is in pulmonary macrophages (Pecqueur et al., 2001, Alves-Guerra et al., 2003). Hyperoxia increases mitochondrial ROS generation (Freeman and Crapo, 1981, Turrens et al., 1982, Brueckl et al., 2006), and UCP2 is rapidly expressed in macrophages under other conditions that increase mitochondrial ROS production (Giardina et al., 2008). This suggests that hyperoxia will also induce UCP2 in pulmonary macrophages. That, in turn, would invite the hypothesis that UCP2 induction in macrophages will curtail the increase in mitochondrial ROS production that accompanies hyperoxia. The work reported here addresses these postulates and explores the regulatory mechanisms behind hyperoxia-induced UCP2 expression in macrophages. 


\section{$\underline{\text { Materials and Methods }}$}

Hyperoxic exposure of animals, collection of lung tissue and bronchoalveolar lavage

Specified pathogen-free, male BALB/c mice at 8-9 wk of age (Animal Resource Centre, Murdoch, Australia) were housed in individually ventilated cages with food and water available ad-libitum. Animal studies were approved by the Animal Ethics Committee of the University of Western Australia (Approval No. RA/3/100/814) and adhered to guidelines established by the National Health and Medical Research Council of Australia. For hyperoxia experiments, cages were enclosed in $38 \mathrm{~cm}$ x $28 \mathrm{~cm}$ x $21 \mathrm{~cm}$ airtight Plexiglas enclosures. Enclosures were flushed with $100 \% \mathrm{O}_{2}$ and then suffused at 1 liter/min to maintain an atmosphere of $\geq 95 \% \mathrm{O}_{2}$ throughout the study period. Oxygen concentration was monitored continuously with a calibrated Pico Technology DD103 $\mathrm{O}_{2}$ probe (Pico Technology, UK) and data logger (Clear State Solutions, Sydney, Australia). Control mice were housed similarly but exposed to atmospheric oxygen concentrations.

For protein and mRNA analysis of whole lung, groups of 5 animals were sacrificed after periods of hyperoxic exposure $(1,4,8$ and $24 \mathrm{~h}$ ) or normoxia. Lungs were collected as previously described (Lan et al., 2004) and immediately placed in ice-cold Dulbecco's PBS. The upper lobes of the right lungs were snap frozen in liquid nitrogen and used for later mRNA analysis.

Bronchoalveolar lavage (BAL) was performed on groups of animals at pre-exposure $(n=10)$, $1 \mathrm{~h}(\mathrm{n}=8)$ and $4 \mathrm{~h}(\mathrm{n}=8)$ of $\mathrm{O}_{2}$ exposure, as previously described (Peters et al., 2010). Differential cell counts were performed on Diff-Quick stained and CD68immunohistochemically labeled BAL cytospin preparations. Macrophages constituted $\geq 95 \%$ of cells in the BAL of all animals at each time point. 
Immunocytochemistry of BAL cells

BAL cells were dual stained for UCP2 and the macrophage marker, CD68, by the following method. Cytospin preparations were initially fixed for 5 min with $4 \%$ paraformaldehyde in PBS, washed with $0.5 \mathrm{M} \mathrm{NaCl} \mathrm{pH} 7.4$ for $5 \mathrm{~min}$, air dried and frozen at $-80^{\circ} \mathrm{C}$ until use. After thawing at room temperature for $10 \mathrm{~min}$, cytospin spots were circled with a PAP pen and given three, 5 min washes in PBS. Cells were then permeabilised for 15 min with PBS containing $0.05 \%$ Triton-X-100 and 10\% normal donkey serum (NDS: Sigma-Aldrich). After blocking in PBS/3\%NDS for $1 \mathrm{~h}$, slides were treated at $4^{\circ} \mathrm{C}$ overnight with goat anti-UCP2 (SC-6525, Santa Cruz, diluted 1:50 in PBS/3\%NDS) or normal goat IgG (SC-2028, Santa Cruz) as the isotype control. After 3 washes with PBS, slides were incubated for $2 \mathrm{~h}$ at room temperature in the dark with Alexa Fluor488 donkey anti-goat IgG (A11055, Invitrogen) diluted 1:500 in PBS/3\%NDS, then washed again 3 times with PBS. Slides were blocked again with $\mathrm{PBS} / 3 \% \mathrm{NDS}$ in the dark for $1 \mathrm{~h}$, incubated at $4^{\circ} \mathrm{C}$ in the dark overnight with rat anti-mouse CD68 (MCA1957GA, AbD SeroTec) diluted 1:250 in PBS/3\%NDS and rewashed 3 times with PBS. They were then incubated for $2 \mathrm{~h}$ at room temperature in the dark with Alexa Fluor568 goat anti-rat IgG (A11077, Invitrogen) diluted 1:250 in PBS $/ 3 \%$ NDS and washed again 3 times with PBS. The specificity of the anti-UCP2 antibody was confirmed by transiently expressing UCP2 in HEK 293 cells to generate a verified standard (Giardina et al., 2008).

Preparations were mounted in ProLong Gold antifade reagent containing DAPI as the nuclear counterstain (AbD SeroTec), sealed and kept in the dark at $4^{\circ} \mathrm{C}$ until viewed on a Nikon A1 confocal microscope (Shinjuku, Tokyo, Japan) at 60X magnification. Captured image files were converted to TIFF files for analysis using ImageJ software (Abramoff et al., 2004). The mean UCP2 signal above background per CD68 positive cell was calculated for each slide. 
For each condition (normoxia, $1 \mathrm{~h}$ hyperoxia and $4 \mathrm{~h}$ hyperoxia), a mean of $\geq 45$ cells per mouse were individually quantitated.

\section{Cell lines and reagents}

The murine macrophage cell line, $\mathrm{RAW}_{264.7}$, was obtained from the American Type Culture Collection (ATCC). Cells were maintained in Dulbecco's Modified Eagle Medium (DMEM: Invitrogen) supplemented with 10\% low endotoxin foetal calf serum (FCS) (Bovogen, Australia), penicillin and gentamicin (DMEM/FCS). Cells were incubated in DMEM/FCS in a humidified atmosphere of $5 \% \mathrm{CO}_{2} / 95 \%$ air at $37^{\circ} \mathrm{C}$ or in hyperoxic conditions as described below. Primary murine bone marrow-derived monocyte/macrophages (BMDM) were isolated from long bones of BALB/c mice, as previously described (Yip et al., 2005) and expanded in $75 \mathrm{~cm}^{2}$ culture flasks for 7 days in DMEM/FCS supplemented with $40 \mathrm{ng} / \mathrm{ml}$ of human macrophage-colony stimulating factor-1 (R\&D Systems) (DMEM/FCS/CSF-1).

Other reagents were supplied by Sigma-Aldrich, except where indicated.

\section{Hyperoxic and normoxic cell culture conditions}

For studies on UCP2 protein and mRNA levels, RAW 264.7 cells $\left(2.5 \times 10^{5}\right)$ and BMDM $\left(8 \times 10^{5}\right)$ were seeded into $60 \mathrm{~mm}$ tissue culture dishes in $3.7 \mathrm{ml}$ of DMEM/FCS or DMEM/FCS/CSF-1, respectively, and cultured for $72 \mathrm{~h}$ prior to hyperoxic or normoxic exposure. For studies on the effects of hyperoxia on $\mathrm{O}_{2}{ }^{--}$production and $\Delta \psi_{\mathrm{m}}$, cells $\left(8 \times 10^{3}\right.$ cells /well, 10 wells per condition) were cultured in clear 96 -well plates for $72 \mathrm{~h}$ in $100 \mu 1$ of appropriate medium prior to exposure. Cultures were then enclosed in a Modular Incubation Chamber (MIC101, Billups Rottenberg Inc., CA) and gassed with $95 \% \mathrm{O}_{2} / 5 \% \mathrm{CO}_{2}$ according to manufacturer's 
instructions, so as to maintain an atmospheric $\mathrm{O}_{2}$ of $95 \%$ throughout the period of incubation. Control cells were maintained similarly, supplied with $95 \%$ air and $5 \% \mathrm{CO}_{2}$.

\section{UCP2 protein analysis}

Following exposure to hyperoxia $(0.5,1,2$ or $4 \mathrm{~h})$ or normoxia, BMDM and $\mathrm{RAW}_{264.7}$ cells were immediately rinsed twice with $5 \mathrm{ml}$ of ice cold DPBS and then lysed in NP40 lysis buffer $\left(10 \mathrm{mM}\right.$ Tris, $50 \mathrm{mM} \mathrm{NaCl}, 30 \mathrm{mM} \mathrm{Na}_{4} \mathrm{P}_{2} \mathrm{O}_{7} .10 \mathrm{H}_{2} \mathrm{O}, 100 \mathrm{mM} \mathrm{NaF}, 5 \mu \mathrm{M} \mathrm{ZnCl} 2,1 \mathrm{mM}$ $\mathrm{NaVO}_{4}, 10 \mathrm{mM}$ sodium beta-glycerophosphate, $80 \mathrm{nM}$ okadaic acid, $\mathrm{pH} 7.0$ containing $1 \%$ NP-40 and $2 \times$ complete protease inhibitors [Roche Diagnostics]).

Lung tissue remaining after removal of the right upper lobe was homogenized in $0.5 \mathrm{ml}$ of $10 \mathrm{mM}$ Tris, $1 \mathrm{mM}$ EDTA, 250mM sucrose $\mathrm{pH} 7.5$ buffer (TES) containing $1 \mathrm{x}$ Roche complete protease inhibitors in an ice cold $2 \mathrm{ml}$ glass Dounce homogenizer using $15-20$

plunger strokes. The homogenate was centrifuged $(1,300 \mathrm{~g})$ at $4^{\circ} \mathrm{C}$ for $10 \mathrm{~min}$. The supernatant was separated and centrifuged at $17,000 \mathrm{~g}$ for 20 min to create a mitochondiaenriched pellet. This was resuspended in $1 \mathrm{ml}$ of TES buffer and reprecipitated by centrifugation at $17,000 \mathrm{~g}$ for $30 \mathrm{~min}$ at $4^{\circ} \mathrm{C}$. The washed mitochondrial pellet was then resuspended in $100 \mu$ l of NP-40 lysis buffer.

\section{Western analysis}

Protein extracts from BMDM, $\mathrm{RAW}_{264.7}$ cells, and lung mitochondrial lysates $(30,20$ or 40 $\mu \mathrm{g}$ respectively) were separated by SDS electrophoresis on precast $4-12 \%$ Bis Tris gels at $200 \mathrm{~V}$ for $1 \mathrm{~h}$ in a Criterion cell (Bio-Rad) and then electro-transferred (100V for $30 \mathrm{~min})$ to PVDF membranes. Membranes were blocked for $1 \mathrm{~h}$ in TTBS (TBS with $0.1 \%$ Tween 20) 
containing 5\% milk powder and 1\% BSA, and then incubated for 90 min with the primary antibody of interest in SignalBoost solution 1 (Immunoreaction Enhancer Kit, Merck Millipore), given two 10 min washes in TTBS and incubated for $1 \mathrm{~h}$ in SignalBoost solution 2 (Immunoreaction Enhancer Kit, Merck Millipore) containing HRP labeled secondary antibodies. After three $10 \mathrm{~min}$ washes in TTBS, the resolved bands were visualized by enhanced chemiluminescence (ECL) detection reagents (GE Healthcare) using a biomolecular imager (LAS 4000, GE Healthcare). Densitometric quantitation of images was performed using ImageQuant TL Imaging Software, Version 7.0 (GE Healthcare). Statistical analysis of treatment effects on UCP2 expression employed data that was normalised for $\beta$ actin or VDAC1 (voltage-dependent anion channel-1) expression.

\section{Antibodies}

Primary antibodies were goat anti-UCP2 (SC-6525, 1:1000, Santa Cruz), monoclonal mouse anti- $\beta$-actin (A-5441, 1: 5000, Sigma-Aldrich), goat anti-VDAC1 (SC-8828, 1:1,000, Santa Cruz) and mouse IgG1 anti MnSOD (M99920/611580, 1:2500, BD Transduction Laboratories). Secondary antibodies used were donkey anti-goat HRP (SC-2020, 1:10 000, Santa Cruz) and sheep anti-mouse HRP (NXA931, 1:10 000, GE Healthcare). Prior to re-probing, membranes were stripped according to published methods (Yeung and Stanley, 2009).

mRNA analysis

Frozen lung samples from animals exposed to hyperoxia were transferred to a liquid nitrogen-chilled Biopulverizer (Biospec Products, OK, USA) and processed according to the manufacturer's instructions. Total mRNA was prepared from the resulting powdered lung by 
following the manufacturer's protocol for animal tissues using the RNeasy ${ }^{\circledR}$ Protect Mini Kit (Qiagen).

Cells that had been exposed to hyperoxia $(0.25,0.5,1,2$ and $4 \mathrm{~h})$ or cultured in normoxic conditions were rinsed twice with $5 \mathrm{ml}$ of ice cold DPBS before lysis in $350 \mu$ l of RNAeasy ${ }^{\circledR}$ lysis buffer. Total mRNA was then isolated.

The Omniscript Reverse Transcriptase Kit (Qiagen) was used for first-strand cDNA synthesis. PCR reactions were completed using an IQ5 Multicolor Real-Time PCR Detection System (Bio-Rad) and SYBR Green PCR MasterMix (Bio-Rad). Samples of cDNAs (equivalent to $20 \mathrm{ng}$ of total mRNA) were amplified by target specific primers for UCP2; (sense) 5'-GTCATCGCCTCCCCTGTTG-3', (antisense) 5'CAGAAAGGTGCCTCCCGAG-3' and Ribosomal Phosphoprotein Large P0 (RPLP0); (sense) 5'-GAGATTCGGGATATGCTGTTG-3', (antisense) 5'TGGAGATTTTCGTGGTGATG-3'. Thermal profiles for the amplification were: $95^{\circ} \mathrm{C}$ for 3 min, then 40 cycles of $95^{\circ} \mathrm{C}$ for $20 \mathrm{sec}, 58^{\circ} \mathrm{C}$ for $60 \mathrm{sec}$ and $72^{\circ} \mathrm{C}$ for $60 \mathrm{sec}$. The specificity of individual primers was validated by end point PCR and gel electrophoresis. Additionally, a melt temperature gradient curve carried out on final reaction products confirmed that a single product had formed. Each sample was normalised using its RPLP0 content as internal reference, and data are expressed as relative abundance of UCP2 mRNA over RPLP0 mRNA.

\section{Mitochondrial membrane potential and superoxide production}

$\mathrm{RAW}_{264.7}$ cells and BMDM cultures, prepared as described above, were exposed to hyperoxia for $0.5,1$ or $2 \mathrm{~h}$ or to normoxia. Mitochondrial $\mathrm{O}_{2}{ }^{--}$production was measured by the dihydroethidium (DHE; Invitrogen) reduction method and $\Delta \psi_{\mathrm{m}}$ was measured using 5,5',6,6'tetrachloro-1,1',3,3'-tetraethylbenzimidazol carbocyanine iodide (JC-1; Invitrogen), as 
previously described (Giardina et al., 2008). Cells were loaded with fluorophore $(0.66 \mu \mathrm{g} / \mathrm{ml}$ JC-1 or $10 \mu \mathrm{M}$ DHE) in complete medium for the final 30 min of incubation. After two washes in Hanks balanced salt solution (HBSS), the fluorescence of cells in HBSS $(100 \mu 1)$ was measured using a microplate reader (POLARstar OPTIMA, BMG, Germany). DNAassociated mitochondrial ethidium (the product of DHE reduction) was measured at $510 \mathrm{~nm}$ excitation and 590nm emission. (Degli Esposti, 2002, Tarpey et al., 2004). $\Delta \psi_{\mathrm{m}}$ was estimated from the ratio of JC-1 red (excitation 520nm; emission $590 \mathrm{~nm}$ ) to green (excitation $485 \mathrm{~nm}$; emission $520 \mathrm{~nm}$ ) fluorescence. Control conditions for these experiments included exposure to the proton ionophore, carbonyl cyanide m-chlorophenylhydrazone (CCCP), which depolarises $\Delta \psi_{\mathrm{m}}$, and to the $\mathrm{F}_{0} \mathrm{~F}_{1}$ ATPase inhibitor oligomycin which hyperpolarises $\Delta \psi_{\mathrm{m}}$.

Intracellular ATP levels

The ATP content of RAW 264.7 cells and BMDM cultures that had been exposed to hyperoxia for $0.5,1$ or $2 \mathrm{~h}$, or to normoxia, were analyzed using the CellTiter-Glo cell viability assay (Promega Corporation), as per manufacturer's instructions. Luminescent intensities (in relative light units; RLU) are directly proportional to ATP concentrations and were detected using a microplate reader (POLARstar OPTIMA, BMG, Germany). Results are normalised to ATP levels (RLU) of normoxic controls.

\section{Statistical analysis}

Statistical differences between control and test groups were analysed by $t$ - test after data normalisation where appropriate. Results are presented as means \pm S.E.M. 


\section{$\underline{\text { Results }}$}

UCP2 protein levels increase in lungs of mice exposed to hyperoxia

Mice complete up to $48 \mathrm{~h}$ of exposure to $\geq 95 \% \mathrm{O}_{2}$ without manifesting clinical evidence of illness. All experiments were concluded by $24 \mathrm{~h}$. Starting from $1 \mathrm{~h}$ of $\geq 95 \% \mathrm{O}_{2}$ exposure, mitochondria-enriched fractions from whole lung extracts exhibited increased levels of UCP2 protein (Figure 1; $\mathrm{P}<0.05)$. Levels were maximal at $4 \mathrm{~h}$ exposure $(\mathrm{P}<0.001)$. Elevated levels persisted to at least $8 \mathrm{~h}$ (Figure 1 ; $\mathrm{P}<0.001$ ), followed by a fall to slightly below preexposure levels at $24 \mathrm{~h}$.

\section{Hyperoxia increases UCP2 levels in bronchoalveolar macrophages}

Alveolar macrophages are the principal cell type found in BAL fluid in healthy mice. BAL was therefore performed on groups of mice before $\mathrm{O}_{2}$ exposure and up until $4 \mathrm{~h}$ of exposure to $\geq 95 \% \mathrm{O}_{2}$, corresponding to the time of maximal levels of UCP2 in lung. Macrophages represented $\geq 95 \%$ of cells in BAL in all mice at all time points, as identified by stained morphology and CD68 positivity (Figure 2A). UCP2 levels were measured by quantitative immunohistochemistry on cytocentrifuge preparations. UCP2 abundance increased from $1 \mathrm{~h}$ and was significantly greater than normoxic controls at $4 \mathrm{~h}$ (Figure $2 \mathrm{~B}$ : $\mathrm{P}<0.005$ ). These

experiments identified macrophages as targets for hyperoxic induction of mitochondrial $\mathrm{UCP} 2$ in the lung.

Non-macrophage cells were present in only low numbers in BAL and did not show a noticeable enhancement of UCP2 signal with hyperoxia. 
Hyperoxia increases UCP2 levels in bone marrow-derived macrophages and murine $R A W_{264.7}$ macrophages.

Alveolar macrophages are terminally-differentiated cells of the bone marrow-derived monocyte/macrophage lineage. We therefore sought to determine whether hyperoxic induction of UCP2 was a general attribute of the lineage, by studying precursor BMDM. BMDM were isolated as described in methods and cultured for up to $4 \mathrm{~h}$ under hyperoxic conditions. UCP2 in BMDM was sufficiently abundant to be measurable on whole cell extracts, without the need for mitochondrial enrichment (Figure 3A and C). There was a rapid induction of UCP2 protein, apparent at $30 \mathrm{~min}$ and significant by $1 \mathrm{~h}(\mathrm{P}<0.05)$, before declining to pre-exposure levels from $2 \mathrm{~h}$. Hyperoxic induction was not unique to primary macrophages, but was also apparent in the $\mathrm{RAW}_{264.7}$ macrophage cell line, with a comparable time course (Figure 3B and D). The $\mathrm{RAW}_{264.7}$ cell line is a relatively well differentiated, Abelson murine leukaemia virus-transformed, murine macrophage line. These experiments showed that the hyperoxic induction of UCP2 in pulmonary alveolar macrophages generalises to other macrophages, both primary and transformed. UCP2 induction precedes adaptive anti-oxidant responses that have been reported in pulmonary tissue or macrophages, including the induction of MnSOD (Cho et al., 2002, Ishii et al., 2000, Schwartz et al., 1996, Warner et al., 1996). Consistent with these previous reports, we found that protein levels for mitochondrial manganese superoxide dismutase (MnSOD) varied by less than 5\% over the 4 $\mathrm{h}$ of hyperoxia in the same BMDM and $\mathrm{RAW}_{264.7}$ cell cultures (Figure 6). BMDM and $\mathrm{RAW}_{264.7}$ cultures remained fully viable for at least $24 \mathrm{~h}$ in hyperoxia, as assessed by trypan blue exclusion (results not shown).

The response to hyperoxia is reminiscent of our earlier observation of increased UCP2 in macrophages after exposure to toxins that increase mitochondrial ROS production (Giardina 
et al., 2008). This suggested that increased UCP2 in hyperoxia may also be related to enhanced mitochondrial ROS production.

\section{Hyperoxia increases UCP2 levels by a post-transcriptional mechanism}

To gain insight into the mechanism of UCP2 regulation by $\mathrm{O}_{2}$ concentration, UCP2 mRNA was measured in whole lung preparations from hyperoxia-exposed mice, in BMDM and in $\mathrm{RAW}_{264.7}$ cells. There was a small $(32 \%)$ increase in UCP2 mRNA at $1 \mathrm{~h}$ in whole lung extracts. This was not reproduced at other time points (Figure 4A). UCP2 mRNA is expressed in a broader range of cells and tissue than the protein (Mattiasson and Sullivan, 2006, Nedergaard and Cannon, 2003), allowing the possibility that the small increment at $1 \mathrm{~h}$ reflected expression in other pulmonary cell types, or that a real increase in macrophage UCP2 mRNA at other times had been overshadowed by stable expression in other pulmonary cell types. We therefore also examined UCP2 mRNA expression in-vitro, in cultures of BMDM and RAW 264.7 macrophages. There was no increase in UCP2 mRNA in BMDM or $\mathrm{RAW}_{264.7}$ cells over a time course that spanned the hyperoxia-induced increases in UCP2 protein in these cells (Figure 4B and 4C). These findings indicated that transcription was, at most, a minor contributor to hyperoxic regulation of UCP2 in pulmonary alveolar macrophages.

UCP2 mRNA levels in whole lung declined significantly at $24 \mathrm{~h}$, similar to changes in mitochondrial UCP2 protein at this time point (Figure 1, Figure 4). 
Functional associations of enhanced UCP2 levels

To better define the functional significance of UCP2 induction in hyperoxia-exposed macrophages, we measured two mitochondrial functions that are closely linked to UCP2 levels, $\Delta \psi_{\mathrm{m}}$ and mitochondrial $\mathrm{O}_{2}{ }^{--}$generation.

Mitochondrial $\mathrm{O}_{2}{ }^{--}$generation was estimated from oxidation of dihydroethidium (DHE) to its DNA-conjugated fluorogenic product, ethidium in BMDM and in $\mathrm{RAW}_{264.7}$ cell cultures. Fifteen minutes of exposure to $95 \% \mathrm{O}_{2}$ increased ethidium fluorescence significantly in both $\mathrm{BMDM}$ and $\mathrm{RAW}_{264.7}$ macrophages, compared with normoxia (Figure 5A and 5B). Thereafter, $\mathrm{O}_{2}{ }^{--}$generation fell to levels significantly lower than baseline, remaining suppressed at $2 \mathrm{~h}$ in BMDM but recovering in $\mathrm{RAW}_{264.7}$ macrophages. After the early burst of production, $\mathrm{O}_{2}{ }^{--}$therefore varied reciprocally with UCP2 levels (Figure 5 and Figure 3), consistent with UCP2 suppression of $\mathrm{O}_{2}{ }^{--}$generation.

UCP2 suppression of mitochondrial ROS generation may be attributable to the reduction in $\Delta \psi_{\mathrm{m}}$ that accompanies an uncoupling function. $\Delta \psi_{\mathrm{m}}$ was therefore measured in BMDM and in $\mathrm{RAW}_{264.7}$ cell cultures using the mitochondrial-potential sensitive fluorophore, JC-1. In each cell type, there was suppression of $\Delta \psi_{\mathrm{m}}$, corresponding to the time of maximal UCP2 induction (Figure 5C and 5D). $\Delta \psi_{\mathrm{m}}$ remained suppressed at $2 \mathrm{~h}$ in BMDM, but had partially recovered in $\mathrm{RAW}_{264.7}$ macrophages, similar to the recovery in $\mathrm{O}_{2}{ }^{-}$generation in that cell line. These results imply that the rapid induction of UCP2 in hyperoxia-exposed macrophages may serve the function of protecting against reactive oxygen stress through lowering $\Delta \psi_{\mathrm{m}}$.

Neither hyperoxia nor the induction of UCP2 compromised ATP production during the $2 \mathrm{~h}$ duration of these experiments (Figure 5E and 5F). There were, in fact, small increases in ATP in both BMDM and $\mathrm{RAW}_{264.7}$ cells at $30 \mathrm{~min}(\mathrm{P}<0.05$ in each case). The maintenance of 
ATP levels argues against the possibility that falling $\Delta \psi_{\mathrm{m}}$ reflected a ROS-induced loss of mitochondrial integrity. 


\section{$\underline{\text { Discussion }}$}

We found that hyperoxia rapidly and transiently increased UCP2 protein levels in macrophages without increasing mRNA. $\Delta \psi_{\mathrm{m}}$ and mitochondrial $\mathrm{O}_{2}{ }^{--}$generation declined after UCP2 induction. Induction was broadly observed in primary and transformed macrophages in-vitro and in lung macrophages. The mouse model used in these studies replicates early events in HALI, before inflammatory and exudative changes impair gas transfer and pulmonary circulatory function (Matute-Bello et al., 2008). During this phase, there is increased mitochondrial ROS production and the opportunity for an anti-oxidant response to control it. The anti-oxidant response has been partly characterised through studies on the Nrf2 and NF- $\mathrm{KB}$ signalling systems in lung and through studies of the regulation of ROS in other cells and tissues, including isolated macrophages (Gore et al., 2010, Cho et al., 2002, Franek et al., 2004). Macrophages are represented in the lung by alveolar macrophages, resident interstitial macrophages and, in pathology, by recruited circulating monocyte/macrophages. Macrophages are notable because of their relatively abundant expression of UCP2 and because UCP2 is induced under circumstances where mitochondrial ROS production increases (Fleury et al., 1997, Giardina et al., 2008). A transient increase in mitochondrial $\mathrm{O}_{2}{ }^{--}$generation preceded in-vitro UCP2 induction in these experiments also.

Increased mitochondrial ROS production has been well demonstrated in response to hyperoxia in other systems, but not generally as early as observed here (Brueckl et al., 2006, Freeman and Crapo, 1981, Turrens et al., 1982). A similarly rapid UCP2 accumulation accompanies pharmacological stimulation of mitochondrial ROS generation in macrophages (Giardina et al., 2008). The observation that UCP2 upregulation followed an initial, hyperoxia-induced burst of mitochondrial $\mathrm{O}_{2}{ }^{-}$generation therefore suggests that mitochondrial $\mathrm{O}_{2}{ }^{--}$itself may be the stimulus for UCP2 induction. 
UCP2 regulates $\Delta \psi_{\mathrm{m}}$ and mitochondrial $\mathrm{O}_{2}{ }^{--}$production (Arsenijevic et al., 2000, Azzu et al., 2010, Negre-Salvayre et al., 1997). The hyperoxic induction of UCP2 in macrophages in our studies was linked chronologically to suppression of $\Delta \psi_{\mathrm{m}}$ and mitochondrial $\mathrm{O}_{2}{ }^{-{ }^{-}}$generation. These are expected consequences of increased functional UCP2 levels. Despite the suppression of $\Delta \psi_{\mathrm{m}}$, there was no fall in ATP levels during hyperoxia, rather there was a small early increase in levels in both BMDM and $\mathrm{RAW}_{264.7}$ macrophages. A similar increase has been seen in lung epithelial cells exposed to hyperoxia (Chambellan et al., 2006). Macrophage energy requirements vary according to their state of differentiation, but are primarily supplied from non-mitochondrial sources during inflammatory activation (Vats et al., 2006), perhaps insulating the energy supply from changes in mitochondrial function.

Although there was a small, very transient induction of UCP2 mRNA in the lungs of hyperoxia-exposed mice, UCP2 mRNA was not induced in isolated primary or transformed macrophages. This is interpreted to mean that hyperoxic induction is through a posttranscriptional mechanism. Post-transcriptional regulation of UCP2 has been previously shown in macrophages exposed to pharmacological inducers of mitochondrial ROS production (Giardina et al., 2008) and in other circumstances (Azzu et al., 2010, Chen et al., 2009). In the INS-1E pancreatic $\beta$-cell line (Azzu et al., 2010), $\Delta \psi_{\mathrm{m}^{-}}$and ATP-dependent transfer of UCP2 to cytosolic proteasomes for degradation has been demonstrated, allowing UCP2 to accumulate under conditions of low $\Delta \psi_{\mathrm{m}}$ or ATP depletion. The microRNA miR133a has also been shown to directly suppression translation of UCP2 mRNA (Chen et al., 2009), but this microRNA is not known to be expressed in macrophages.

Induction of UCP2 is early and transient. UCP2 induction precedes other adaptive antioxidant responses mediated through NF- $\mathrm{KB}$ or Nrf2 pathways in macrophages (Cho et al., 2002, Ishii et al., 2000, Schwartz et al., 1996). In whole lung, UCP2 induction gives way to an overall loss of UCP2 protein and UCP2 mRNA from $24 \mathrm{~h}$. This may correspond with the 
appearance of other, less immediate, anti-oxidant defences including mitochondrial MnSOD (White and Tsan, 2001, Warner et al., 1996). In macrophage culture MnSOD responses emerge at 12 to $24 \mathrm{~h}$ of oxidant exposure (White and Tsan, 2001, Warner et al., 1996). Invivo, induced antioxidant responses to hyperoxia are typically apparent at 48 to $72 \mathrm{~h}$ (Cho et al., 2002, Nagata et al., 2007). Alternatively, the late decline in UCP2 level may be pathological, reflecting mitochondrial damage through ROS exposure (Scatena et al., 2004), or loss of mitochondrial content during mitochondrial steps of apoptosis. Apoptosis is well described in later stages of HALI (Mantell et al., 1997). The experiments reported here focussed on the phase of HALI that precedes clinical illness, so were not designed to test whether UCP2 induction in macrophages influences clinical severity or mortality in HALI, or the human illnesses to which HALI contributes, BPD and ARDS.

\section{Conclusions}

Macrophages in lung tissue respond to hyperoxia by rapid induction of UCP2, most likely through a post-transcriptional mechanism. This is a very early response, preceding other adaptive anti-oxidant responses through NF- $\mathrm{BB}$ or Nrf2 pathways. The subsequent falls in $\Delta \psi_{\mathrm{m}}$ and mitochondrial $\mathrm{O}_{2}{ }^{-}$are consistent with known actions of UCP2. By restraining mitochondrial ROS production, UCP2 induction may limit inappropriate pro-inflammatory activation of macrophages in HALI, potentially including the human diseases ARDS and BPD. 


\section{Acknowledgement}

This work was supported by Project Grant 572638 from the National Health and Medical Research Council of Australia.

\section{Declaration of Interest}

The authors report no conflict of interest. 


\section{Figure Legends}

Figure 1. Hyperoxia induces mitochondrial UCP2 in mouse lung. (A) UCP2 abundance in mitochondria-enriched extracts from whole lung of mice exposed to $\geq 95 \% \mathrm{O}_{2}$ for up to $24 \mathrm{~h}$, normalised to VDAC1 levels. $\mathrm{N}=5$ mice at each time point. $* \mathrm{P}<0.05 ; * * \mathrm{P}<0.001$. (B) Representative western analysis for UCP2 and VDAC1 in mitochondria-enriched extracts from mouse whole lung over a $24 \mathrm{~h}$ time course.

Figure 2. Hyperoxia induces UCP2 in pulmonary alveolar macrophages. (A) Representative images of BAL cytocentrifuge specimens obtained from mice exposed to hyperoxia for up to $4 \mathrm{~h}$. Upper panels show anti-UCP2 antibody binding (normoxia, $1 \mathrm{~h}$ hyperoxia and $4 \mathrm{~h}$ hyperoxia) and isotype control antibody binding (right panel). Lower panels show colocalised anti-CD68 antibody binding in the same fields. The nuclear counterstain is DAPI. (B) Immunohistochemical quantitation of UCP2 antibody binding in BAL macrophages of mice exposed to $\geq 95 \% \mathrm{O}_{2}$ for up to $4 \mathrm{~h}$, expressed as a ratio to signal in isotype control antibody preparations. $\mathrm{N}=10$ (normoxia), 8 (hyperoxia $1 \mathrm{~h}$ ) and 8 (hyperoxia $4 \mathrm{~h}$ ) animals. * $\mathrm{P}<0.005$

Figure 3. Hyperoxia-induced UCP2 in macrophages. (A) Hyperoxia induces UCP2 protein in whole cell extracts of cultured murine BMDM and (B) $\mathrm{RAW}_{264.7}$ macrophages. Results are from 3 - 4 independent experiments for each time point, normalised to $\beta$-actin levels. ${ }^{*} \mathrm{P}<$ 0.05. (C) and (D) Representative western analysis for UCP2 and $\beta$-actin in whole cell extracts of BMDM (C) and RAW 264.7 (D) cultures exposed to hyperoxia for up to $4 \mathrm{~h}$. 
Figure 4. Effect of hyperoxic exposure on UCP2 mRNA. (A) Hyperoxia causes a small and transient rise in UCP2 mRNA in whole lung of exposed mice, followed by a fall at $24 \mathrm{~h} .{ }^{*} \mathrm{P}$ $<0.05 . \mathrm{N}=5$ mice at each time point. (B) The early rise in UCP2 mRNA in whole lung was not reproduced in isolated BMDM or (C) $\mathrm{RAW}_{264.7}$ macrophages over $4 \mathrm{~h}$ of exposure to hyperoxia. $\mathrm{N}=3$ for each time point. Data are normalised to RPLP0 mRNA expression in the same specimens.

Figure 5. Mitochondrial $\mathrm{O}_{2}{ }^{--}$generation and $\Delta \psi_{\mathrm{m}}$ during hyperoxia and UCP2 induction. (A) and (B) Exposure to $95 \% \mathrm{O}_{2}$ transiently increases mitochondrial $\mathrm{O}_{2}{ }^{\circ-}$ production in $\mathrm{BMDM}$ and $\mathrm{RAW}_{264.7}$ macrophages at $15 \mathrm{~min}$, followed by a fall in production that is sustained to $2 \mathrm{~h}$ in BMDM and returns to baseline by $2 \mathrm{~h}$ in $\mathrm{RAW}_{264.7}$ macrophages. ( $\mathrm{C}$ and $\left.\mathrm{D}\right) \mathrm{A}$ corresponding suppression of $\Delta \psi_{\mathrm{m}}$ is also sustained to $2 \mathrm{~h}$ in BMDM but partially returns to baseline at $2 \mathrm{~h}$ in $\mathrm{RAW}_{264.7}$ macrophages. $\Delta \psi_{\mathrm{m}}$ is estimated by spectral shift of the mitochondrial fluorophore, JC1. (E and F) ATP levels are not compromised by $2 \mathrm{~h}$ exposure to $95 \% \mathrm{O}_{2}$, in fact increasing transiently at $30 \mathrm{~min} . \mathrm{N} \geq 5$ independent experiments in each case. $* \mathrm{P}<0.05 ; * * \mathrm{P}<0.01$.

Figure 6 Four hours of hyperoxia does not induce expression of MnSOD protein in either (A) BMDM or (B) RAW $_{264.7}$ macrophages. MnSOD expression is normalised to $\beta$-actin expression. Data is from the same experiments as Figure 3. 


\section{References}

Abramoff, M. D., Magalhaes, P. J. \& Ram, S. J. 2004. Image Processing with ImageJ. Biophotonics International, 11, 36-42.

Altemeier, W. A. \& Sinclair, S. E. 2007. Hyperoxia in the intensive care unit: why more is not always better. Curr Opin Crit Care, 13, 73-8.

Alves-Guerra, M. C., Rousset, S., Pecqueur, C., Mallat, Z., Blanc, J., Tedgui, A., Bouillaud, F., Cassard-Doulcier, A. M., Ricquier, D. \& Miroux, B. 2003. Bone marrow transplantation reveals the in vivo expression of the mitochondrial uncoupling protein 2 in immune and nonimmune cells during inflammation. J Biol Chem, 278, 42307-12.

Arsenijevic, D., Onuma, H., Pecqueur, C., Raimbault, S., Manning, B. S., Miroux, B., Couplan, E., Alves-Guerra, M. C., Goubern, M., Surwit, R., Bouillaud, F., Richard, D., Collins, S. \& Ricquier, D. 2000. Disruption of the uncoupling protein-2 gene in mice reveals a role in immunity and reactive oxygen species production. Nat Genet, 26, 435-9.

Azzu, V., Jastroch, M., Divakaruni, A. S. \& Brand, M. D. 2010. The regulation and turnover of mitochondrial uncoupling proteins. Biochim Biophys Acta, 1797, 785-91.

Blackwell, T. S., Hipps, A. N., Yamamoto, Y., Han, W., Barham, W. J., Ostrowski, M. C., Yull, F. E. \& Prince, L. S. 2011. NF-kappaB signaling in fetal lung macrophages disrupts airway morphogenesis. J Immunol, 187, 2740-7.

Bourbon, J., Boucherat, O., Chailley-Heu, B. \& Delacourt, C. 2005. Control mechanisms of lung alveolar development and their disorders in bronchopulmonary dysplasia. Pediatr Res, $57,38 \mathrm{R}-46 \mathrm{R}$.

Branson, R. D. \& Robinson, B. R. 2011. Oxygen: when is more the enemy of good? Intensive Care Med, 37, 1-3. 
Brueckl, C., Kaestle, S., Kerem, A., Habazettl, H., Krombach, F., Kuppe, H. \& Kuebler, W. M. 2006. Hyperoxia-induced reactive oxygen species formation in pulmonary capillary endothelial cells in situ. Am J Respir Cell Mol Biol, 34, 453-63.

Chambellan, A., Cruickshank, P. J., Mckenzie, P., Cannady, S. B., Szabo, K., Comhair, S. A. \& Erzurum, S. C. 2006. Gene expression profile of human airway epithelium induced by hyperoxia in vivo. Am J Respir Cell Mol Biol, 35, 424-35.

Chen, X., Wang, K., Chen, J., Guo, J., Yin, Y., Cai, X., Guo, X., Wang, G., Yang, R., Zhu, L., Zhang, Y., Wang, J., Xiang, Y., Weng, C., Zen, K., Zhang, J. \& Zhang, C. Y. 2009. In vitro evidence suggests that miR-133a-mediated regulation of uncoupling protein 2 (UCP2) is an indispensable step in myogenic differentiation. J Biol Chem, 284, 5362-9.

Cho, H. Y., Jedlicka, A. E., Reddy, S. P., Kensler, T. W., Yamamoto, M., Zhang, L. Y. \& Kleeberger, S. R. 2002. Role of NRF2 in protection against hyperoxic lung injury in mice. Am J Respir Cell Mol Biol, 26, 175-82.

D'angio, C. T., Lomonaco, M. B., Johnston, C. J., Reed, C. K. \& Finkelstein, J. N. 2004. Differential roles for NF-kappa B in endotoxin and oxygen induction of interleukin-8 in the macrophage. Am J Physiol Lung Cell Mol Physiol, 286, L30-6.

D'angio, C. T., Sinkin, R. A., Lomonaco, M. B. \& Finkelstein, J. N. 1995. Interleukin-8 and monocyte chemoattractant protein-1 mRNAs in oxygen-injured rabbit lung. Am J Physiol, 268, L826-31.

De Graaff, A. E., Dongelmans, D. A., Binnekade, J. M. \& De Jonge, E. 2011. Clinicians' response to hyperoxia in ventilated patients in a Dutch ICU depends on the level of FiO2. Intensive Care Med, 37, 46-51.

Degli Esposti, M. 2002. Measuring mitochondrial reactive oxygen species. Methods, 26, 33540. 
Donnelly, S. C., Strieter, R. M., Kunkel, S. L., Walz, A., Robertson, C. R., Carter, D. C., Grant, I. S., Pollok, A. J. \& Haslett, C. 1993. Interleukin-8 and development of adult respiratory distress syndrome in at-risk patient groups. Lancet, 341, 643-7.

Fleury, C., Neverova, M., Collins, S., Raimbault, S., Champigny, O., Levi-Meyrueis, C., Bouillaud, F., Seldin, M. F., Surwit, R. S., Ricquier, D. \& Warden, C. H. 1997. Uncoupling protein-2: a novel gene linked to obesity and hyperinsulinemia. Nat Genet, 15, 269-72.

Fracica, P. J., Knapp, M. J., Piantadosi, C. A., Takeda, K., Fulkerson, W. J., Coleman, R. E., Wolfe, W. G. \& Crapo, J. D. 1991. Responses of baboons to prolonged hyperoxia: physiology and qualitative pathology. J Appl Physiol, 71, 2352-62.

Franek, W. R., Morrow, D. M., Zhu, H., Vancurova, I., Miskolci, V., Darley-Usmar, K., Simms, H. H. \& Mantell, L. L. 2004. NF-kappaB protects lung epithelium against hyperoxiainduced nonapoptotic cell death-oncosis. Free Radic Biol Med, 37, 1670-9.

Frank, L., Bucher, J. R. \& Roberts, R. J. 1978. Oxygen toxicity in neonatal and adult animals of various species. J Appl Physiol, 45, 699-704.

Freeman, B. A. \& Crapo, J. D. 1981. Hyperoxia increases oxygen radical production in rat lungs and lung mitochondria. J Biol Chem, 256, 10986-92.

Freeman, B. A. \& Crapo, J. D. 1982. Biology of disease: free radicals and tissue injury. Lab Invest, 47, 412-26.

Fridovich, I. 1978. The biology of oxygen radicals. Science, 201, 875-80.

Giardina, T. M., Steer, J. H., Lo, S. Z. \& Joyce, D. A. 2008. Uncoupling protein-2 accumulates rapidly in the inner mitochondrial membrane during mitochondrial reactive oxygen stress in macrophages. Biochim Biophys Acta, 1777, 118-29.

Gore, A., Muralidhar, M., Espey, M. G., Degenhardt, K. \& Mantell, L. L. 2010. Hyperoxia sensing: from molecular mechanisms to significance in disease. $J$ Immunotoxicol, 7, 239-54. Halliwell, B. 2007. Biochemistry of oxidative stress. Biochem Soc Trans, 35, 1147-50. 
Ishii, T., Itoh, K., Takahashi, S., Sato, H., Yanagawa, T., Katoh, Y., Bannai, S. \& Yamamoto, M. 2000. Transcription factor Nrf2 coordinately regulates a group of oxidative stressinducible genes in macrophages. J Biol Chem, 275, 16023-9.

Kizaki, T., Suzuki, K., Hitomi, Y., Taniguchi, N., Saitoh, D., Watanabe, K., Onoe, K., Day, N. K., Good, R. A. \& Ohno, H. 2002. Uncoupling protein 2 plays an important role in nitric oxide production of lipopolysaccharide-stimulated macrophages. Proc Natl Acad Sci U S A, 99, 9392-7.

Lan, R. S., Stewart, G. A., Goldie, R. G. \& Henry, P. J. 2004. Altered expression and in vivo lung function of protease-activated receptors during influenza A virus infection in mice. Am J Physiol Lung Cell Mol Physiol, 286, L388-98.

Limon-Pacheco, J. \& Gonsebatt, M. E. 2009. The role of antioxidants and antioxidant-related enzymes in protective responses to environmentally induced oxidative stress. Mutat Res, 674, $137-47$.

Mantell, L. L., Kazzaz, J. A., Xu, J., Palaia, T. A., Piedboeuf, B., Hall, S., Rhodes, G. C., Niu, G., Fein, A. F. \& Horowitz, S. 1997. Unscheduled apoptosis during acute inflammatory lung injury. Cell Death Differ, 4, 600-7.

Mattiasson, G. \& Sullivan, P. G. 2006. The emerging functions of UCP2 in health, disease, and therapeutics. Antioxid Redox Signal, 8, 1-38.

Matute-Bello, G., Frevert, C. W. \& Martin, T. R. 2008. Animal models of acute lung injury. Am J Physiol Lung Cell Mol Physiol, 295, L379-99.

Miwa, S., St-Pierre, J., Partridge, L. \& Brand, M. D. 2003. Superoxide and hydrogen peroxide production by Drosophila mitochondria. Free Radic Biol Med, 35, 938-48.

Morgan, M. J. \& Liu, Z. G. 2011. Crosstalk of reactive oxygen species and NF-kappaB signaling. Cell Res, 21, 103-15. 
Nagata, K., Iwasaki, Y., Yamada, T., Yuba, T., Kono, K., Hosogi, S., Ohsugi, S., Kuwahara, H. \& Marunaka, Y. 2007. Overexpression of manganese superoxide dismutase by Nacetylcysteine in hyperoxic lung injury. Respir Med, 101, 800-7.

Nedergaard, J. \& Cannon, B. 2003. The 'novel' 'uncoupling' proteins UCP2 and UCP3: what do they really do? Pros and cons for suggested functions. Exp Physiol, 88, 65-84.

Negre-Salvayre, A., Hirtz, C., Carrera, G., Cazenave, R., Troly, M., Salvayre, R., Penicaud, L. \& Casteilla, L. 1997. A role for uncoupling protein-2 as a regulator of mitochondrial hydrogen peroxide generation. Faseb J, 11, 809-15.

Nicholls, D. G. \& Locke, R. M. 1984. Thermogenic mechanisms in brown fat. Physiol Rev, $64,1-64$.

Pagliari, L. J., Perlman, H., Liu, H. \& Pope, R. M. 2000. Macrophages require constitutive NF-kappaB activation to maintain A1 expression and mitochondrial homeostasis. Mol Cell Biol, 20, 8855-65.

Pecqueur, C., Alves-Guerra, M. C., Gelly, C., Levi-Meyrueis, C., Couplan, E., Collins, S., Ricquier, D., Bouillaud, F. \& Miroux, B. 2001. Uncoupling protein 2, in vivo distribution, induction upon oxidative stress, and evidence for translational regulation. J Biol Chem, 276, 8705-12.

Pepperl, S., Dorger, M., Ringel, F., Kupatt, C. \& Krombach, F. 2001. Hyperoxia upregulates the NO pathway in alveolar macrophages in vitro: role of AP-1 and NF-kappaB. Am $J$ Physiol Lung Cell Mol Physiol, 280, L905-13.

Perl, M., Lomas-Neira, J., Venet, F., Chung, C. S. \& Ayala, A. 2011. Pathogenesis of indirect (secondary) acute lung injury. Expert Rev Respir Med, 5, 115-26.

Peters, T., Mann, T. S. \& Henry, P. J. 2010. Inhibitory influence of protease-activated receptor 2 and E-prostanoid receptor stimulants in lipopolysaccharide models of acute airway inflammation. J Pharmacol Exp Ther, 335, 424-33. 
Scatena, R., Messana, I., Martorana, G. E., Gozzo, M. L., Lippa, S., Maccaglia, A., Bottoni, P., Vincenzoni, F., Nocca, G., Castagnola, M. \& Giardina, B. 2004. Mitochondrial damage and metabolic compensatory mechanisms induced by hyperoxia in the U-937 cell line. $J$ Biochem Mol Biol, 37, 454-9.

Schwartz, M. D., Moore, E. E., Moore, F. A., Shenkar, R., Moine, P., Haenel, J. B. \& Abraham, E. 1996. Nuclear factor-kappa B is activated in alveolar macrophages from patients with acute respiratory distress syndrome. Crit Care Med, 24, 1285-92.

Tarpey, M. M., Wink, D. A. \& Grisham, M. B. 2004. Methods for detection of reactive metabolites of oxygen and nitrogen: in vitro and in vivo considerations. Am J Physiol Regul Integr Comp Physiol, 286, R431-44.

Teshima, Y., Akao, M., Jones, S. P. \& Marban, E. 2003. Uncoupling protein-2 overexpression inhibits mitochondrial death pathway in cardiomyocytes. Circ Res, 93, 192200.

Tsushima, K., King, L. S., Aggarwal, N. R., De Gorordo, A., D'alessio, F. R. \& Kubo, K. 2009. Acute lung injury review. Intern Med, 48, 621-30.

Turrens, J. F., Freeman, B. A., Levitt, J. G. \& Crapo, J. D. 1982. The effect of hyperoxia on superoxide production by lung submitochondrial particles. Arch Biochem Biophys, 217, 40110.

Vats, D., Mukundan, L., Odegaard, J. I., Zhang, L., Smith, K. L., Morel, C. R., Wagner, R. A., Greaves, D. R., Murray, P. J. \& Chawla, A. 2006. Oxidative metabolism and PGC-1beta attenuate macrophage-mediated inflammation. Cell Metab, 4, 13-24.

Warner, B. B., Stuart, L., Gebb, S. \& Wispe, J. R. 1996. Redox regulation of manganese superoxide dismutase. Am J Physiol, 271, L150-8. 
White, J. E. \& Tsan, M. F. 2001. Differential induction of TNF-alpha and MnSOD by endotoxin: role of reactive oxygen species and NADPH oxidase. Am J Respir Cell Mol Biol, 24, 164-9.

Yeung, Y. G. \& Stanley, E. R. 2009. A solution for stripping antibodies from polyvinylidene fluoride immunoblots for multiple reprobing. Anal Biochem, 389, 89-91.

Yip, K. H., Zheng, M. H., Steer, J. H., Giardina, T. M., Han, R., Lo, S. Z., Bakker, A. J., Cassady, A. I., Joyce, D. A. \& Xu, J. 2005. Thapsigargin modulates osteoclastogenesis through the regulation of RANKL-induced signaling pathways and reactive oxygen species production. J Bone Miner Res, 20, 1462-71. 
Figure 1

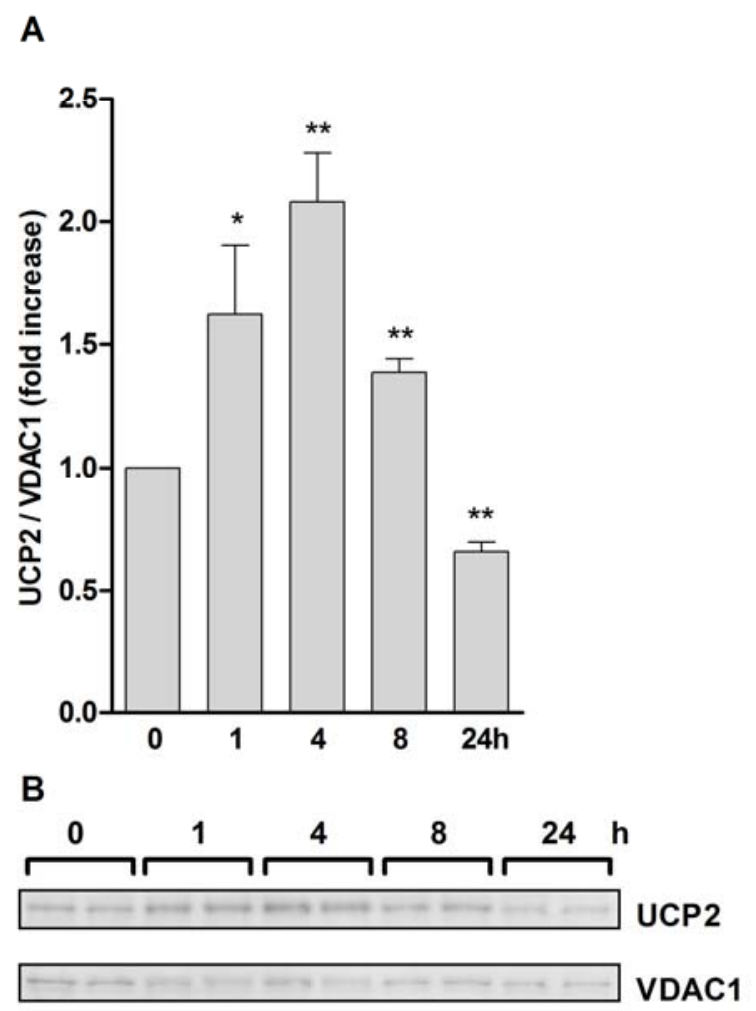


Figure 2

A

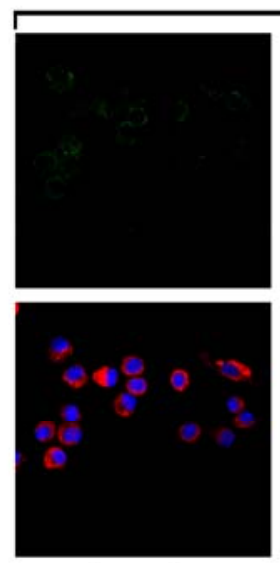

Normoxia
Anti-UCP2 Antibody
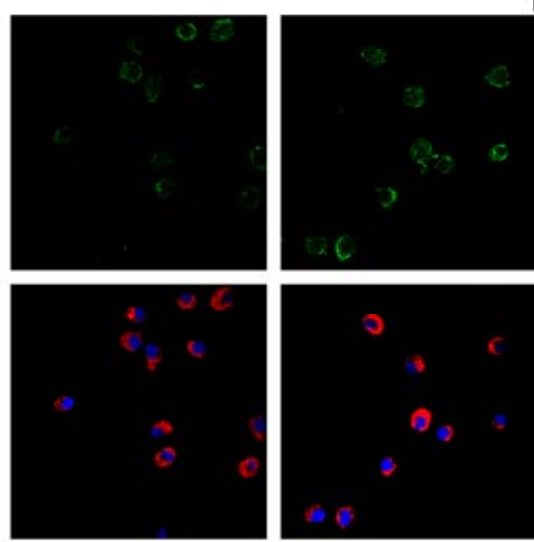

$1 \mathrm{hr}$ Hyperoxia

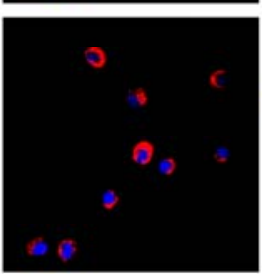

4hr Hyperoxia
B

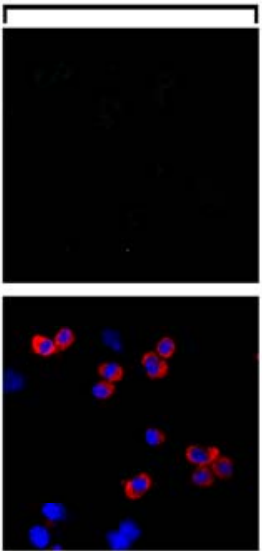

4hr Hyperoxia

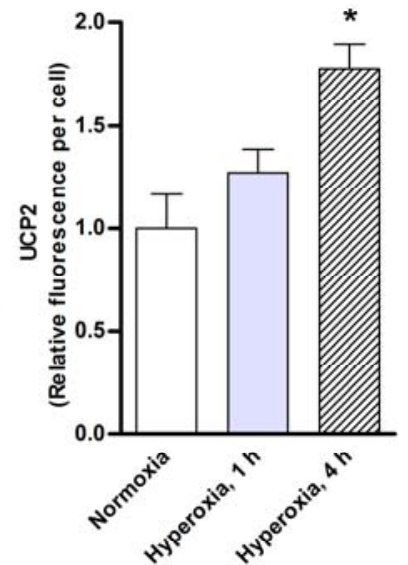


Figure 3

A

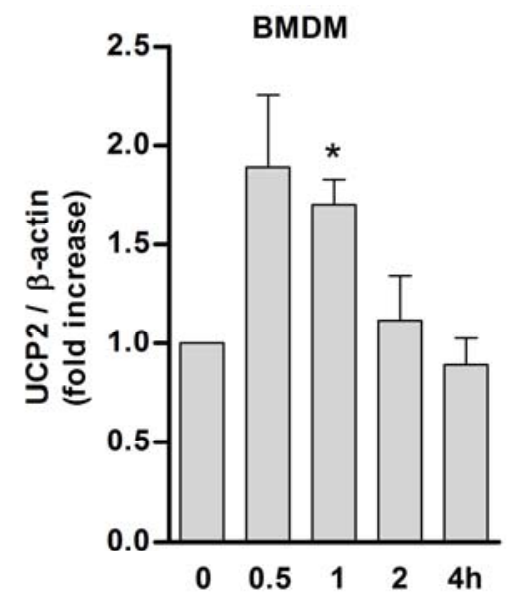

C

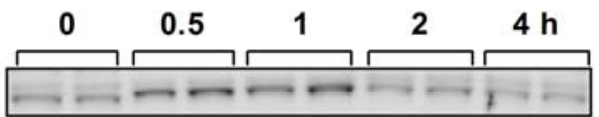

$-\cdots+\cdots-\infty-\cdots$

BMDM
B

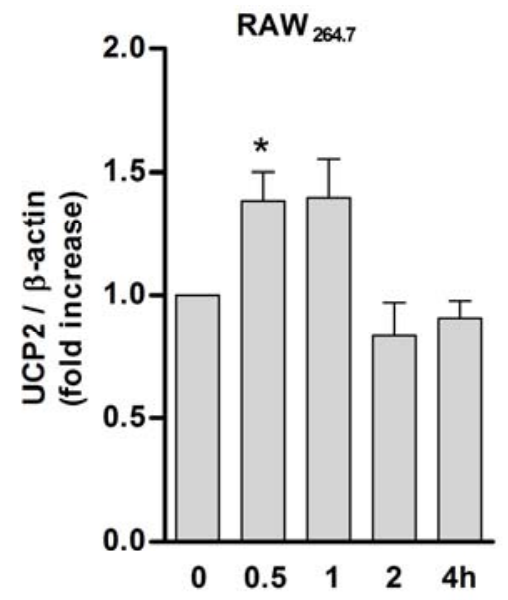

D

UCP2

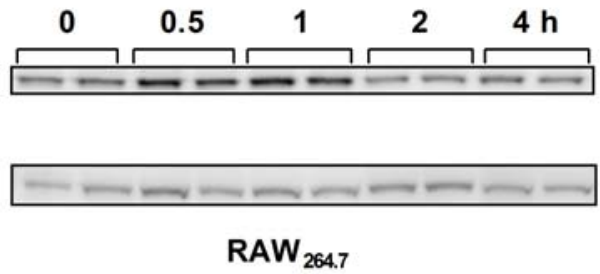


Figure 4

A

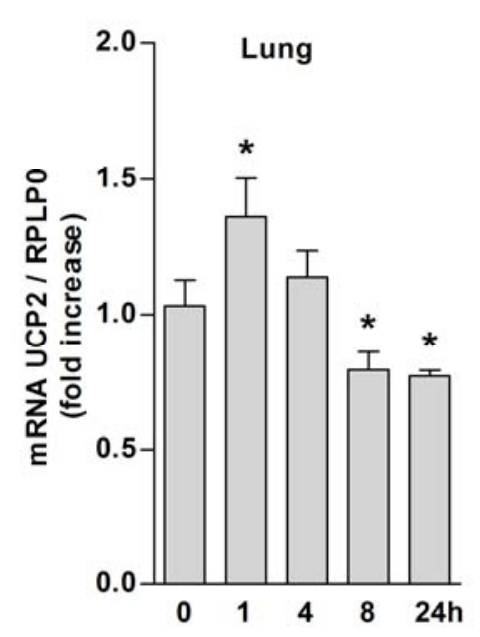

B
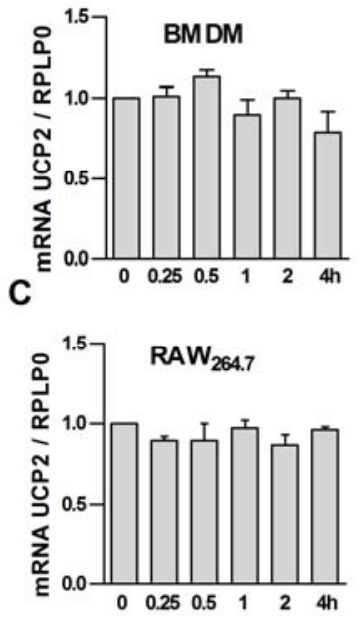
Figure 5

A

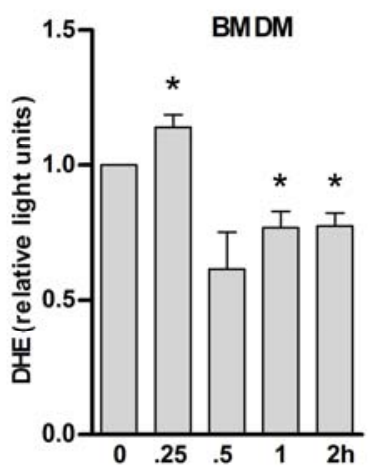

C

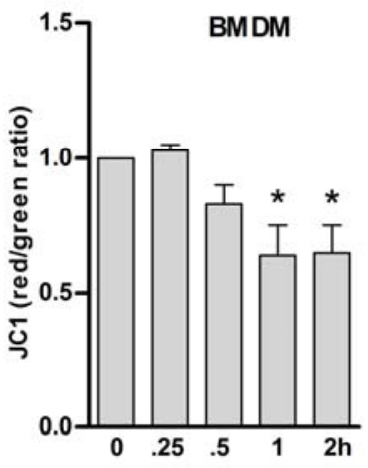

E

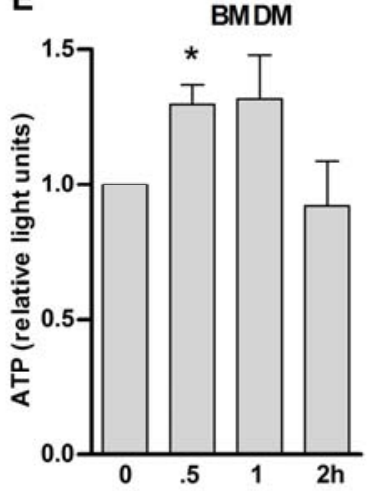

B

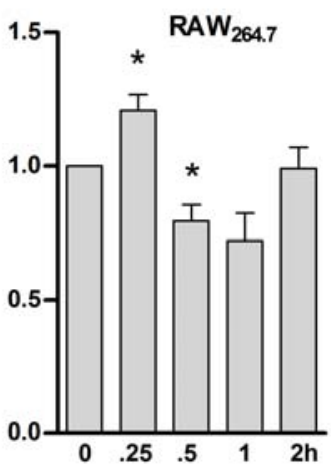

D

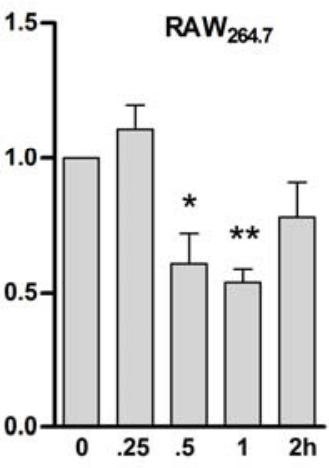

F $\quad$ RAW $_{264.7}$

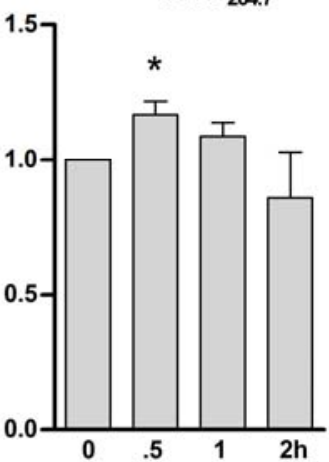


Figure 6

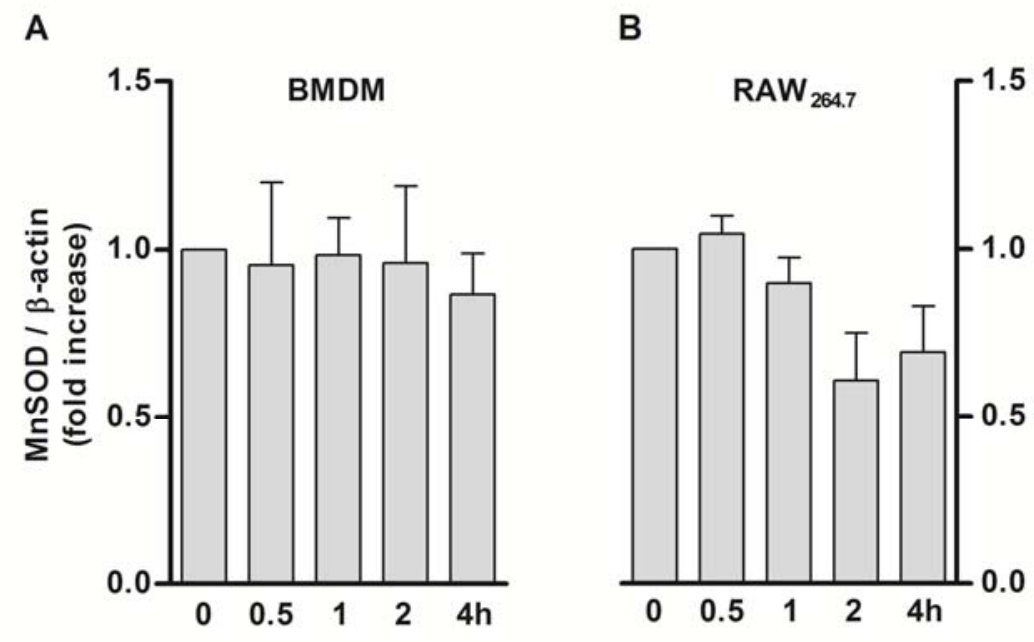

